\title{
BMJ
}

\section{Secular decline in mortality from coronary heart disease in adults with diabetes mellitus: cohort study}

\author{
Ane Cecilie Dale, research fellow, medical doctor, ${ }^{1,4}$ Lars J Vatten, professor, ${ }^{2,5}$ Tom Ivar Nilsen, associate \\ professor, ${ }^{3}$ Kristian Midthjell, associate professor, ${ }^{2}$ Rune Wiseth, professor ${ }^{1,4}$
}

${ }^{1}$ Department of Circulation and Medical Imaging, Norwegian

University of Science and

Technology

${ }^{2}$ Department of Public Health, Norwegian University of Science and Technology

${ }^{3}$ Human Movement Science

Programme, Norwegian University of Science and Technology

${ }^{4}$ Department of Cardiology, St Olav's University Hospital, NO

7030 Trondheim, Norway

${ }^{5}$ International Agency for Research on Cancer, Lyon, France Correspondence to: A C Dale ane.c.dale@ntnu.no

BMJ 2008::1-6 doi:10.1136/bmj.39582.447998.BE

\section{ABSTRACT}

Objective To examine trends in fatal coronary heart disease in adults with and without diabetes.

Design Cohort study.

Setting Two surveys of the Nord-Trøndelag health study (HUNT), a population based study in Norway.

Participants 74914 men and women from the first survey (1984-6) and 64829 from the second survey (1995-7).

Main outcome measure Age specific mortality from coronary heart disease among adults with and without diabetes during two consecutive nine year follow-up periods.

Results A total of 2623 men and 1583 women died from coronary heart disease. Mortality rates were substantially lower during the most recent follow-up period: among men aged 70-79 without diabetes, deaths per 1000 person years declined from 16.38 to 8.79 (reduction 48\%, 95\% confidence interval $39 \%$ to $55 \%$ ) and among women aged $70-79$ from 6.84 to 2.68 (62\%, $52 \%$ to $70 \%)$. Among the same age group with diabetes, deaths per 1000 person years in men declined from 38.97 to $17.89(54 \%, 32 \%$ to $69 \%$ ) and in women from 28.15 to 11.83 (59\%, 37\% to $73 \%)$. The reduction was more noticeable in age groups younger than 70 at baseline, and less pronounced among people aged 80 or more. Mortality from coronary heart disease was more than twofold higher in people with than without diabetes, with a slightly stronger association in women. The difference in mortality by diabetes status remained almost unchanged from the first to the second survey.

Conclusion The strong general reduction in mortality rates from coronary heart disease from the first to the second follow-up period also benefited people with diabetes, but the more than twofold higher mortality from coronary heart disease associated with diabetes persisted over time.

\section{INTRODUCTION}

Mortality rates from coronary heart disease have declined in the Western world ${ }^{1-5}$ during the past 30 years, most rapidly from the mid-1980s, and faster in men than in women. The reason for the decrease includes a reduced burden of risk factors related to cardiovascular disease ${ }^{6}$ a lower incidence of coronary heart disease, and improved survival as a result of better treatment. ${ }^{15-11}$ Over the same timespan the incidence and prevalence of diabetes have increased. ${ }^{12-19}$ Compared with the general population, people with diabetes have a 2-4-fold higher mortality from coronary heart disease, ${ }^{20}$ but many studies have also shown a secular decline in mortality from coronary heart disease in people with diabetes, ${ }^{1921-23}$ although the evidence for this is not supported by all studies. ${ }^{2425}$

We compared mortality rates from coronary heart disease over two consecutive nine year periods in adults who reported diabetes in the 1980s and in the 1990 s. We also studied mortality rates from coronary heart disease among adults without diabetes.

\section{METHODS}

Two large population surveys were carried out in Nord-Trøndelag county, Norway: the first wave (HUNT 1) in 1984-6 and the second wave (HUNT 2) in 1995-7. Nord-Trøndelag is in the middle of Norway and is regarded as fairly representative of the country. The population is stable and ethnically homogeneous, with only a small percentage $(3 \%)$ of people of nonwhite origin. In both studies residents aged 20 years or older were invited to participate. A total of 74977 $(88.1 \%)$ adults participated in the first survey and $66140(71.2 \%)$ in the second survey.

Participants in the first survey responded to a questionnaire and attended a clinical examination that included measurements of blood pressure, pulse, body weight, and height. ${ }^{26}$ In the present analysis we included 74914 people (36 722 men and 38192 women; a total of 2100 reported to have diabetes) who had valid responses to the variables of body weight, height, systolic and diastolic blood pressure, and diabetes status.

Participants in the second survey completed a more comprehensive questionnaire than in the first survey. ${ }^{27}$ In the analysis we included 64829 people (30 367 men and 34462 women; a total of 1951 reported to have diabetes) who responded to the questionnaire, attended the clinical examination, and had valid data on body weight, height, systolic and diastolic blood pressure, and diabetes status.

\section{Definitions}

From the baseline questionnaire we collected information on prevalent diabetes and history of 


\section{Table 1| Baseline characteristics of two cohorts of Nord-Trøndelag health study. Bracketed values are $95 \%$ confidence intervals unless stated otherwise}

\begin{tabular}{|c|c|c|c|c|}
\hline \multirow[b]{2}{*}{ Characteristics } & \multicolumn{2}{|c|}{ Diabetes } & \multicolumn{2}{|c|}{ No diabetes } \\
\hline & First survey & Second survey & First survey & Second survey \\
\hline \multicolumn{5}{|l|}{ Men: } \\
\hline No (\% of total) & $932(2.5)$ & $940(3.1)$ & $35790(97.5)$ & $29427(96.9)$ \\
\hline Mean age (years) & $66.2(65.3$ to 67.1$)$ & 64.3 (63.4 to 65.2$)$ & 48.5 (48.3 to 48.7$)$ & $49.3(49.1$ to 49.5$)$ \\
\hline Mean glucose* level (mmol/l) & $8.6(8.4$ to 8.9$)$ & $10.0(9.7$ to 10.3$)$ & $5.5(5.5$ to 5.5$)$ & $5.4(5.4$ to 5.4$)$ \\
\hline Mean body mass index $\left(\mathrm{kg} / \mathrm{m}^{2}\right)$ & $26.3(26.0$ to 26.5$)$ & $28.0(27.7$ to 28.2$)$ & $25.2(25.2$ to 25.2$)$ & $26.4(26.4$ to 26.4$)$ \\
\hline Mean systolic blood pressure $(\mathrm{mm} \mathrm{Hg})$ & $154.0(152.3$ to 155.7$)$ & 150.8 (149.4 to 152.3$)$ & $141.2(140.9$ to 141.4$)$ & $139.7(139.5$ to 140.0$)$ \\
\hline \% hypertensive† & $53.4(50.2$ to 56.7$)$ & $51.4(48.1$ to 54.6$)$ & 33.3 (32.8 to 33.8$)$ & $26.0(25.5$ to 26.5$)$ \\
\hline$\%$ current smokers & 21.5 (18.9 to 24.2$)$ & 20.3 (18.8 to 23.0$)$ & 30.8 (30.3 to 31.2) & $28.4(27.9$ to 29.0$)$ \\
\hline$\%$ obeseł & $14.6(12.4$ to 17.0$)$ & 27.6 (24.7 to 30.5$)$ & 7.5 (7.2 to 7.8$)$ & $13.8(13.4$ to 14.2$)$ \\
\hline$\%$ with baseline cardiovascular disease $\S$ & 28.8 (25.9 to 31.8$)$ & 31.5 (28.5 to 35.6$)$ & $7.6(7.3$ to 7.9$)$ & $9.3(9.0$ to 9.6$)$ \\
\hline \multicolumn{5}{|l|}{ Women: } \\
\hline No (\% of total) & $1168(3.1)$ & $1011(2.9)$ & $37024(96.6)$ & 33451 (96.9) \\
\hline Mean age (years) & $69.8(69.1$ to 70.5$)$ & $67.6(66.7$ to 68.4$)$ & $49.4(49.2$ to 49.6$)$ & $49.6(49.4$ to 49.7$)$ \\
\hline Mean glucose* $(\mathrm{mmol} / \mathrm{l})$ & $8.4(8.2$ to 8.7$)$ & $9.2(9.0$ to 9.5$)$ & $5.1(5.1$ to 5.1$)$ & $5.3(5.3$ to 5.3$)$ \\
\hline Mean body mass index $\left(\mathrm{kg} / \mathrm{m}^{2}\right)$ & $28.0(27.7$ to 28.3$)$ & 29.9 (29.6 to 30.3$)$ & $25.0(25.0$ to 25.1$)$ & $26.2(26.1$ to 26.2$)$ \\
\hline Mean systolic blood pressure $(\mathrm{mm} \mathrm{Hg})$ & $163.8(162.1$ to 165.4$)$ & $157.3(155.7$ to 158.9$)$ & $138.1(137.8$ to 138.4$)$ & $135.3(135.1$ to 135.6$)$ \\
\hline \% hypertensive $†$ & $64.4(61.6$ to 67.1$)$ & $57.2(54.1$ to 60.2$)$ & $30.9(30.4$ to 31.4$)$ & $22.2(21.7$ to 22.6$)$ \\
\hline$\%$ current smokers & $9.3(7.7$ to 11.1$)$ & $12.4(10.4$ to 14.6$)$ & $25.8(25.4$ to 26.3$)$ & $29.3(28.8$ to 29.8$)$ \\
\hline$\%$ obese & $31.2(28.5$ to 33.9$)$ & 43.8 (40.7 to 46.9$)$ & $12.8(12.5$ to 13.2$)$ & $17.6(17.2$ to 18.0$)$ \\
\hline$\%$ with baseline cardiovascular disease $\S$ & 28.1 (25.5 to 30.8$)$ & 25.8 (23.1 to 28.6$)$ & 5.0 (4.8 to 5.2$)$ & 5.5 (5.2 to 5.7$)$ \\
\hline
\end{tabular}

*Random measurement.

$\dagger$ Systolic blood pressure $\geq 140 / 90 \mathrm{~mm} \mathrm{Hg}$ or taking antihypertensive drugs.

$\ddagger$ Body mass index $\geq 30.0 \mathrm{~kg} / \mathrm{m}^{2}$.

§Known angina, stroke, or myocardial infarction, as reported at baseline.

cardiovascular disease. We defined those who responded positively to the question "Do you have or have you had diabetes?" to have diabetes. Participants were specifically asked about history of angina, myocardial infarction, and stroke, and we classified those who responded positively to one or more relevant questions as having established cardiovascular disease.

Body mass index was calculated as weight $(\mathrm{kg})$ divided by the squared value of height $(\mathrm{m})$ and classified according to the definitions of the World Health Organization $\left(<18.5 \mathrm{~kg} / \mathrm{m}^{2}=\right.$ underweight, $18.5-24.9$ $\mathrm{kg} / \mathrm{m}^{2}=$ normal weight, $25-29.9 \mathrm{~kg} / \mathrm{m}^{2}=$ overweight, $\geq 30 \mathrm{~kg} / \mathrm{m}^{2}=$ obesity). Random non-fasting glucose $(\mathrm{mmol} / \mathrm{l})$ was measured in participants aged 40 or more. We defined hypertension as a blood pressure of $140 / 90 \mathrm{~mm} \mathrm{Hg}$ or more or as current use of antihypertensive drugs. Exercise as reported in the first survey was divided into three levels; no regular exercise, exercise once weekly, and exercise twice or more weekly. Exercise reported in the second survey was categorised into four levels; no regular exercise, 2-3 hours of light weekly activity, three hours of light activity or one hour of hard activity weekly, and more than one hour of hard activity weekly. On the basis of self reporting of smoking status, participants were classified into three categories: current smoker, former smoker, or never smoker. We dichotomised education according to duration: less than 13 years or 13 or more years.

\section{Follow-up}

We obtained information on causes of death by linking data from the first and second surveys to the Causes of
Death Registry at Statistics Norway, which receives the death certificates of all Norwegian citizens. Deaths were classified according to the international classification of diseases (ninth and 10th revisions, respectively): coronary heart disease 410-4 and I20-5, cardiovascular disease 390-459 and I00-99, and stroke 430-8 and I6069.9 .

For the follow-up of mortality after the first survey, we calculated individual person time from the date of participation at baseline (1984-6) until date of death from coronary heart disease or from other causes, or until the end of follow-up on 31 December 1993. Follow-up after the second survey was calculated as person time from the date of participation at baseline (1995-7) until date of death from coronary heart disease or from other causes, or until the end of follow-up on 31 December 2004.

\section{Statistical analysis}

We calculated age specific mortality rates from coronary heart disease among men and women with and without diabetes during nine years of follow-up after both the first survey and the second survey. A Mantel-Cox comparison was used to calculate mortality rate ratios, with 95\% confidence intervals, between the two follow-up periods by sex, age group, and diabetes status.

We also estimated hazard ratios $195 \%$ confidence intervals) of mortality from coronary heart disease between people with and without diabetes. The analysis was done separately for each follow-up period for the whole population and stratified by sex, using 
Cox regression analysis. Analyses were adjusted for age (continuous), body mass index (continuous), hypertension (yes, no), smoking status (current, former, never or unknown), exercise level (none, regular, unknown), and level of education (low, high, unknown). We tested for statistical interaction between study period (first survey or second survey) and prevalence of diabetes in relation to mortality from coronary heart disease during follow-up. Departure from the proportional hazards assumption was evaluated using graphical procedures (log-log plots). We used Stata for Windows (version 9.2) and SPSS for Windows (version 14) for the statistical analyses.

\section{RESULTS}

In men the prevalence of diabetes was higher in the second survey than in the first survey, whereas in women the prevalence of diabetes did not increase over time (table 1). Among those with diabetes, mean body mass index was about two units higher in the second than in the first survey. Among those without diabetes mean body mass index was about one unit higher in the second than in the first survey. Systolic blood pressure in the second survey was generally lower in all groups, with the greatest reduction in people with diabetes. A lower proportion of men but higher proportion of women reported current smoking in the second survey.

During the two follow-up periods 15365 people died (table 2). The proportion of deaths from coronary heart disease among people with diabetes at baseline decreased from the first to the second survey (men, $19.7 \%$ to $10.3 \%$; women, $18.2 \%$ to $8.2 \%$ ). Among people without diabetes at baseline, a similar reduction occurred in the proportion of deaths caused by coronary heart disease from the first to the second survey (men, $4.6 \%$ to $2.4 \%$; women, $2.4 \%$ to $1.2 \%$ ).

Among people without diabetes, mortality rates from coronary heart disease were substantially lower during the follow-up period after the second survey (1995-2004) than after the first survey (1984-93), and among men the reduction in mortality rates from coronary heart disease was more pronounced in younger age groups (table 3). Thus in people without diabetes at baseline the mortality rate from coronary heart disease in men aged 70-79 declined from 16.38 to 8.79 deaths per 1000 person years (reduction 48\%, 95\% confidence interval $39 \%$ to $55 \%$ ) and in women aged $70-79$, it declined from 6.84 to 2.68 deaths per 1000 person years (reduction 62\%, 52\% to 70\%). In people with diabetes at baseline the mortality rate from coronary heart disease in men aged 70-79 declined from 38.97 to 17.89 deaths per 1000 person years (reduction 54\%, 32\% to 69\%) and in women aged 70-79 declined from 28.15 to 11.83 deaths per 1000 person years (reduction 59\%, 37\% to 73\%). From the first survey to the second survey the reduction in mortality from coronary heart disease was stronger in age groups younger than 70 at baseline and less pronounced among those aged 80 or more (table 3 ). Mortality rates in women generally resembled those in men about 10 years younger.

The higher mortality associated with diabetes was roughly the same for both follow-up periods (adjusted hazard ratio $2.48,95 \%$ confidence interval 2.19 to 2.81 $v 2.24,1.91$ to 2.64$)$. In sex specific analyses, the association of diabetes with mortality from coronary heart disease was slightly stronger in women than in men for both follow-up periods. Thus the hazard ratios for women with diabetes at baseline compared with those without diabetes at baseline were 2.87 (2.39 to 3.44) after the first survey and 2.71 (2.12 to 3.47) after the second survey. In men the corresponding values were 2.16 (1.81 to 2.57 ) and 1.95 (1.57 to 2.42 ; table 4$)$.

\section{DISCUSSION}

We found a strong and general decline in mortality rates from coronary heart disease irrespective of age, sex, and diabetes status during two consecutive nine years of follow-up after the first and second surveys of the Nord-Trøndelag health study. Throughout the two follow-up periods mortality from coronary heart disease in people with diabetes at baseline was more than twofold higher than in those without diabetes at baseline, even if the population with diabetes experienced a reduction in mortality rates from coronary heart disease similar to that of the general population.

In agreement with other studies we found that people who reported diabetes in the most recent cohort (second survey) were on average younger ${ }^{1528}$ and the prevalence of diabetes was higher than in the cohort from the first survey. Hypertension was more prevalent in people with diabetes. This might partly explain the increased risk for coronary heart disease associated with diabetes. ${ }^{62930}$ The prevalence of hypertension decreased from the first survey to the second, but in the second survey still more than half the population with

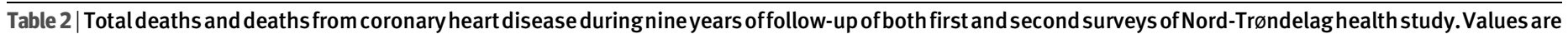
numbers (percentage of people in each cell; $95 \%$ confidence interval)

\begin{tabular}{|c|c|c|c|c|}
\hline \multirow[b]{2}{*}{ Variables } & \multicolumn{2}{|c|}{ Diabetes } & \multicolumn{2}{|c|}{ No diabetes } \\
\hline & First survey & Second survey & First survey & Second survey \\
\hline \multicolumn{5}{|l|}{ Men: } \\
\hline Deaths & $487(52.3 ; 49.0$ to 55.5$)$ & $313(33.3 ; 30.3$ to 36.4$)$ & $4893(13.7 ; 13.3$ to 14.0$)$ & 2879 (9.8; 9.4 to 10.1$)$ \\
\hline Coronary heart disease deaths & $184(19.7 ; 17.2$ to 22.4$)$ & $97(10.3 ; 8.4$ to 12.4$)$ & $1638(4.6 ; 4.4$ to 4.8$)$ & $704(2.4 ; 2.2$ to 2.6$)$ \\
\hline \multicolumn{5}{|l|}{ Women: } \\
\hline Deaths & $598(51.2 ; 48.3$ to 54.1$)$ & $352(34.8 ; 31.9$ to 37.8$)$ & 3537 (9.6; 9.3 to 9.9) & $2306(6.9 ; 6.6$ to 7.2$)$ \\
\hline Coronary heart disease deaths & $212(18.2 ; 16.0$ to 20.5$)$ & $83(8.2 ; 6.6$ to 10.1$)$ & $883(2.4 ; 2.2$ to 2.5$)$ & $405(1.2 ; 1.1$ to 1.3$)$ \\
\hline
\end{tabular}


Table 3| Mortality rates from coronary heart disease afternineyears' follow-up of both first and second surveys of Nord-Trøndelaghealth study, and mortality rate ratios from coronary heart disease after second versus first survey

\begin{tabular}{|c|c|c|c|c|c|c|c|}
\hline \multirow[b]{2}{*}{$\begin{array}{l}\text { Age (years) at } \\
\text { baseline }\end{array}$} & \multicolumn{3}{|c|}{ First survey } & \multicolumn{3}{|c|}{ Second survey } & \multirow[b]{2}{*}{$\begin{array}{c}\text { Rate ratios }(95 \% \mathrm{Cl}) \text { second } \\
\qquad \text { first survey }\end{array}$} \\
\hline & Person years & $\begin{array}{c}\text { No of } \\
\text { deaths }\end{array}$ & Mortality rate* $(95 \% \mathrm{Cl})$ & Person years & $\begin{array}{c}\text { No of } \\
\text { deaths }\end{array}$ & Mortality rate* $(95 \% \mathrm{Cl})$ & \\
\hline \multicolumn{8}{|l|}{ Men } \\
\hline \multicolumn{8}{|l|}{ No diabetes: } \\
\hline$<60$ & 199282 & 152 & $0.76(0.65$ to 0.89$)$ & 159942 & 41 & 0.26 (0.19 to 0.35$)$ & $0.26(0.19$ to 0.37$)$ \\
\hline $60-69$ & 50175 & 364 & $7.25(6.55$ to 8.04$)$ & 35127 & 83 & 2.36 (1.91 to 2.93$)$ & $0.33(0.26$ to 0.42$)$ \\
\hline $70-79$ & 36620 & 600 & $16.38(15.12$ to 17.75$)$ & 30025 & 264 & 8.79 (7.79 to 9.92$)$ & $0.52(0.45$ to 0.61$)$ \\
\hline$\geq 80$ & 14684 & 520 & 35.41 (32.50 to 38.59 ) & 13453 & 316 & $23.49(21.04$ to 26.23$)$ & 0.67 (0.59 to 0.77$)$ \\
\hline \multicolumn{8}{|l|}{ Diabetes: } \\
\hline$<60$ & 1525 & 7 & $4.59(2.19$ to 9.63$)$ & 1992 & 1 & $0.50(0.07$ to 3.56$)$ & 0.07 (0.01 to 0.84$)$ \\
\hline $60-69$ & 1464 & 45 & $30.73(22.95$ to 41.16$)$ & 1440 & 11 & $7.70(4.26$ to 13.90$)$ & 0.27 (0.14 to 0.52$)$ \\
\hline $70-79$ & 1925 & 75 & 38.97 (31.08 to 48.87 ) & 2068 & 37 & 17.89 (12.97 to 24.70$)$ & $0.46(0.31$ to 0.68$)$ \\
\hline$\geq 80$ & 1119 & 56 & 50.07 (38.53 to 65.06$)$ & 1096 & 48 & $43.79(33.00$ to 58.10$)$ & $0.92(0.62$ to 1.36$)$ \\
\hline \multicolumn{8}{|l|}{ Women } \\
\hline \multicolumn{8}{|l|}{ No diabetes: } \\
\hline$<60$ & 200991 & 28 & $0.14(0.10$ to 0.20$)$ & 179967 & 4 & 0.02 (0.01 to 0.06$)$ & $0.13(0.05$ to 0.38$)$ \\
\hline $60-69$ & 52072 & 87 & 1.67 (1.35 to 2.06$)$ & 38796 & 35 & $0.90(0.65$ to 1.26$)$ & $0.56(0.38$ to 0.83$)$ \\
\hline $70-79$ & 43588 & 298 & $6.84(6.10$ to 7.66$)$ & 35404 & 95 & 2.68 (2.19 to 3.28$)$ & $0.38(0.30$ to 0.48$)$ \\
\hline$\geq 80$ & 21590 & 468 & 21.68 (19.80 to 23.73 ) & 21480 & 271 & $12.62(11.20$ to 14.21$)$ & $0.59(0.50$ to 0.68$)$ \\
\hline \multicolumn{8}{|l|}{ Diabetes: } \\
\hline$<60$ & 1160 & 2 & 1.72 (0.43 to 6.89$)$ & 1587 & 1 & 0.63 (0.09 to 4.47) & $0.26(0.02$ to 3.85$)$ \\
\hline $60-69$ & 1645 & 25 & 15.20 (10.27 to 22.50$)$ & 1173 & 2 & 1.71 (0.43 to 6.68) & 0.12 (0.03 to 0.51$)$ \\
\hline $70-79$ & 2842 & 80 & 28.15 (22.61 to 35.04$)$ & 2367 & 28 & $11.83(8.17$ to 17.13$)$ & $0.41(0.27$ to 0.63$)$ \\
\hline$\geq 80$ & 2014 & 104 & $51.63(42.60$ to 62.57$)$ & 2125 & 52 & 24.47 (18.65 to 32.12$)$ & $0.50(0.36$ to 0.71$)$ \\
\hline
\end{tabular}

*Per 1000 person years.

diabetes had hypertension. This suggests that antihypertensive treatment in people with diabetes could have improved during the past decades and that people with diabetes could have benefited both in relation to cardiovascular complications and cardiovascular death. None the less, indications are that further improvements in the treatment of hypertension could still be achieved. ${ }^{2931}$

From the first survey to the second the prevalence of obesity (body mass index $>30$ ) increased in all groups, but this increase was more noticeable in men than in women. Similar observations have been made in other populations. ${ }^{932}$ In our study, obesity was twice as prevalent in people with diabetes and more prevalent in women than in men with diabetes. Obesity increases the risk for diabetes, ${ }^{913141833}$ and obesity, either alone or in combination with diabetes, increases the risk of mortality from coronary heart disease, although the increase seems to be moderate. ${ }^{34}$ It would therefore be expected that the higher prevalence of obesity in the second survey would yield a slightly higher risk of fatal coronary heart disease than after the first survey. Our results, however, suggest the opposite: women with diabetes showed the largest reduction in mortality rates from coronary heart disease from the first survey to the second survey. This seemingly paradoxical finding could have several explanations. A sharp increase in body mass index has occurred during recent years and follow-up in our study may not be sufficiently long to capture the influence of the general weight gain. Also, widespread use of more effective medical treatment $^{91035}$ after the second survey may have resulted in lower blood pressure and lower prevalence of other risk factors ${ }^{6}$ and could have outweighed the

Table 4 | Hazard ratios of death from coronary heart disease in people with diabetes compared with people without diabetes, by sex, during nine years' follow-up of both first and second surveys Nord-Trøndelag health study

\begin{tabular}{|c|c|c|c|c|}
\hline \multirow[b]{2}{*}{ Variable } & \multicolumn{2}{|c|}{ Men } & \multicolumn{2}{|c|}{ Women } \\
\hline & $\begin{array}{l}\text { Age and sex adjusted } \\
\text { hazard ratio }(95 \% \mathrm{Cl})\end{array}$ & $\begin{array}{l}\text { Multivariable* adjusted } \\
\text { hazard ratio }(95 \% \mathrm{Cl})\end{array}$ & $\begin{array}{l}\text { Age and sex adjusted } \\
\text { hazard ratio }(95 \% \mathrm{Cl})\end{array}$ & $\begin{array}{l}\text { Multivariable* adjusted } \\
\text { hazard ratio }(95 \% \mathrm{Cl})\end{array}$ \\
\hline \multicolumn{5}{|l|}{ First survey: } \\
\hline No diabetes & 1 (Reference) & 1 (Reference) & 1 (Reference) & 1 (Reference) \\
\hline Diabetes & 2.11 (1.81 to 2.46$)$ & $2.16(1.81$ to 2.57$)$ & 3.19 (2.74 to 3.72$)$ & 2.87 (2.39 to 3.44$)$ \\
\hline \multicolumn{5}{|l|}{ Second survey: } \\
\hline No diabetes & 1 (Reference) & 1 (Reference) & 1 (Reference) & 1 (Reference) \\
\hline Diabetes & 2.03 (1.64 to 2.51$)$ & 1.95 (1.57 to 2.42$)$ & 2.53 (2.0 to 3.2$)$ & 2.71 (2.12 to 3.47$)$ \\
\hline
\end{tabular}

*Adjusted for age, sex, hypertension, body mass index, smoking, exercise, and education. 


\section{WHAT IS ALREADY KNOWN ON THIS TOPIC}

Mortality rates from coronary heart disease have declined in the Western world during the past 30 years, most rapidly from the mid-1980s

People with diabetes have a 2-4-fold higher mortality from coronary heart disease

\section{WHAT THIS STUDY ADDS}

The strong general decline in mortality coronary heart disease has also benefited people with diabetes

The more than twofold higher risk of dying from coronary heart disease in men and women with diabetes has persisted over time

relatively weak ${ }^{34}$ effect of the higher prevalence of obesity.

The proportion of men who were current smokers decreased from the first survey to the second survey, irrespective of diabetes status, whereas the proportion of women who were current smokers increased. Smoking status therefore cannot explain the decline in fatal coronary heart disease among women with diabetes in this study.

People with diabetes have a higher burden of risk factors for cardiovascular disease than those without diabetes. Despite adjustment for conventional risk factors,$^{36}$ our results showed that people with diabetes still had more than a twofold higher mortality from coronary heart disease.

Other studies have also shown that mortality from coronary heart disease has decreased over the past decades, and it seems that patients with diabetes have also benefited from this reduction. ${ }^{1921-23}$ We found a reduction in mortality rates over time for both men and women with diabetes, and our results are consistent with those of others. ${ }^{2122425}$ One study, ${ }^{24}$ however, found only a moderate reduction in mortality from coronary heart disease in men with diabetes, whereas another study ${ }^{21}$ reported a greater reduction in people with diabetes. The decline in mortality from coronary heart disease that we found for women with diabetes is consistent with some ${ }^{21}$ but not with other studies. ${ }^{2425}$

In our study a particularly noticeable reduction in mortality from coronary heart disease from the first follow-up period to the second follow-up occurred in younger age groups. A relatively lower reduction in older age groups has also been observed by others, ${ }^{22-24}$ but some studies found that all age groups have gone through a period with similar reduction in mortality from coronary heart disease. ${ }^{35}$ Our finding could reflect age as a dominant factor but also that less intensive primary and secondary prevention is applied to elderly people. ${ }^{37}$ It is also possible that both incidence and case fatality from cardiovascular disease could have been reduced as a result of better primary prevention and more effective treatment, and that people with prevalent cardiovascular disease now experience longer survival than before.

The awareness of the higher cardiovascular risk associated with diabetes and impaired glucose tolerance has probably intensified cardioprotective treatment in these patients. Lower mortality may be a result of several factors, including a reduced burden of risk factors, ${ }^{935}$ lower incidence of acute myocardial infarction, ${ }^{3838}$ improved treatment in the acute phase of coronary events, ${ }^{81039}$ and longer survival resulting from aggressive secondary prevention. ${ }^{383840}$ The exact impact of each of these factors is not clear, ${ }^{7}$ but it was recently estimated ${ }^{935}$ that $42-47 \%$ of the decline in mortality from coronary heart disease from 1980 to 2000 can be explained by evidence based therapies, mostly related to secondary prevention after acute myocardial infarction, followed by improved treatment during the acute phase of coronary syndromes. Between $44 \%$ and $58 \%$ of the reduction was attributed to a reduced burden of risk factors, although this reduction may partly be offset by the increase in mortality from coronary heart disease resulting from the increase in body mass index and prevalence of diabetes. ${ }^{935}$ The observation period of the present study coincides with changes in treatment ${ }^{9353940}$ that could have contributed to the decline in mortality from coronary heart disease, irrespective of diabetes status.

Our study has some limitations. Diabetes was defined by self reporting and this could be a source of misclassification. A separate study based on the data from the Nord-Trøndelag health study, however, showed that self reported diabetes was correct in $96.5 \%$ of the cases. ${ }^{41}$ Other studies have also shown that self reporting of diabetes is valid in most cases. ${ }^{4243}$ From the start of the first survey to the end of follow-up after the second survey the prevalence of diabetes increased in the general population, although mean random glucose levels in people who reported diabetes were not substantially different in either survey. None the less, a proportion of people without known diabetes at baseline probably developed the disease during follow-up, but we could not take this change in disease status into account in the analysis. It should also be noted that a change in the definition of death from coronary heart disease occurred from the first followup period to the second follow-up period. This should not, however, affect the mortality ratio between people with and without diabetes within the same follow-up period.

We found that during follow-up of mortality over two consecutive nine year periods, the risk of death from coronary heart disease was more than twofold higher in people with diabetes. We also found that mortality rates from coronary heart disease decreased substantially in all age groups irrespective of sex and diabetes status. This suggests that people with diabetes have also benefited from the overall decline in mortality from coronary heart disease.

Nord-Trøndelag health (HUNT) study is a collaboration between HUNT Research Centre, Faculty of Medicine, Norwegian University of Science and Technology, the Norwegian Institute of Public Health, and NordTrøndelag county council.

Contributors: KM was responsible for the original collection of data and interpreted the findings. ACD and RW conceived the article, analysed the data, and wrote the paper. LJV and TIN analysed and interpreted the data and wrote the paper. RW is guarantor of the study. 
Funding: ACT received research fellowship grants from the liaison committee for central Norway regional health authority and the Norwegian University of Science and Technology.

Competing interests: None declared.

Ethical approval: This study was approved by the regional committee for medical research ethics.

Provenance and peer review: Not commissioned; externally peer reviewed.

1 Reikvam A, Hagen TP. Markedly changed age distribution among patients hospitalized for acute myocardial infarction. Scand Cardiovasc / 2002:36:221-4.

2 Lampe FC, Morris RW, Walker M, Shaper AG, Whincup PH. Trends in rates of different forms of diagnosed coronary heart disease, 1978 to 2000: prospective, population based study of British men. BMJ 2005;330:1046-9.

3 Ergin A, Muntner P, Sherwin R, He J. Secular trends in cardiovascular disease mortality, incidence, and case fatality rates in adults in the United States. Am J Med 2004;117:219-27.

4 Levi F, Lucchini F, Negri E, La Vecchia C. Trends in mortality from cardiovascular and cerebrovascular diseases in Europe and other areas of the world. Heart 2002;88:119-24.

5 Rosamond WD, Chambless LE, Folsom AR, Cooper LS, Conwill DE, Clegg $L$, et al. Trends in the incidence of myocardial infarction and in mortality due to coronary heart disease, 1987 to 1994 . N Engl J Med 1998;339:861-7.

6 Imperatore G, Cadwell BL, Geiss L, Saadinne JB, Williams DE, Ford ES, et al. Thirty-year trends in cardiovascular risk factor levels among US adults with diabetes: national health and nutrition examination surveys, 1971-2000. Am J Epidemiol 2004;160:531-9.

7 Rosamond WD, Folsom AR, Chambless LE, Wang CH. Coronary heart disease trends in four United States communities. The atherosclerosis risk in communities (ARIC) study 1987-1996. Int Epidemiol 2001;30(suppl 1):S17-22.

8 McGovern PG, Jacobs DR, Shahar E, Arnett DK, Folsom AR, Blackburn $\mathrm{H}$, et al. Trends in acute coronary heart disease mortality, morbidity, and medical care from 1985 through 1997: the Minnesota heart survey. Circulation 2001:104:19-24.

9 Ford ES, Ajani UA, Croft JB, Critchley JA, Labarthe DR, Kottke TE, et al. Explaining the decrease in U.S. deaths from coronary disease, 1980 2000. N Engl J Med 2007;356:2388-98.

10 Saaddine JB, Cadwell B, Gregg EW, Engelgau MM, Vinicor F, Imperatore G, et al. Improvements in diabetes processes of care and intermediate outcomes: United States, 1988-2002. Ann Intern Med 2006;144:465-74

11 Laatikainen T, Critchley J, Vartiainen E, Salomaa V, Ketonen M, Capewell S. Explaining the decline in coronary heart disease mortality in Finland between 1982 and 1997. Am J Epidemiol 2005;162:764-73.

12 Harris MI, Flegal KM, Cowie CC, Eberhardt MS, Goldstein DE, Little RR, et al. Prevalence of diabetes, impaired fasting glucose, and impaired glucose tolerance in U.S. adults. The third national health and nutrition examination survey, 1988-1994. Diabetes Care 1998;21:518-24.

13 Gregg EW, Cadwell BL, Cheng YJ, Cowie CC, Williams DE, Geiss L et al. Trends in the prevalence and ratio of diagnosed to undiagnosed diabetes according to obesity levels in the US Diabetes Care 2004;27:2806-12.

14 Mokdad AH, Ford ES, Bowman BA, Dietz WH, Vinicor F, Bales VS, et al. Prevalence of obesity, diabetes, and obesity-related health risk factors, 2001. JAMA 2003;289:76-9.

15 Mokdad AH, Ford ES, Bowman BA, Nelson D, Engelgau MM, Vinicor F, et al. Diabetes trends in the US: 1990-1998. Diabetes Care 2000;23:1278-83.

16 Mokdad AH, Bowman BA, Ford ES, Vinicor F, Marks JS, Koplan JP. The continuing epidemics of obesity and diabetes in the United States. JAMA 2001;286:1195-200.

17 Burke JP, Williams K, Gaskill SP, Hazuda HP, Haffner SM, Stern MP. Rapid rise in the incidence of type 2 diabetes from 1987 to 1996: results from the San Antonio heart study. Arch Intern Med 1999;159:1450-6.

18 Fox CS, Pencina MJ, Meigs JB, Vasan RS, Levitzky YS, D’Agostino RB Trends in the incidence of type 2 diabetes mellitus from the 1970s to the 1990s: the Framingham heart study. Circulation 2006;113:2914-8.

19 Lipscombe LL, Hux JE. Trends in diabetes prevalence, incidence, and mortality in Ontario, Canada 1995-2005: a population-based study. Lancet 2007;369:750-6.

20 Kannel WB, McGee DL. Diabetes and glucose tolerance as risk factors for cardiovascular disease: the Framingham study. Diabetes Care $1979 ; 2: 120-6$
21 Fox CS, Coady S, Sorlie PD, Levy D, Meigs JB D'Agostino Sr RB, et al. Trends in cardiovascular complications of diabetes. JAMA 2004;292:2495-9.

22 Thomas RJ, Palumbo PJ, Melton LJ 3rd, Roger VL, Ransom J, O’Brien PC, et al. Trends in the mortality burden associated with diabetes mellitus: a population-based study in Rochester, Minn, 1970-1994. Arch Intern Med 2003;163:445-51.

23 Booth GL, Kapral MK, Fung K, Tu JV. Recent trends in cardiovascular complications among men and women with and without diabetes. Diabetes Care 2006;29:32-7.

24 Gu K, Cowie CC, Harris MI. Diabetes and decline in heart disease mortality in US adults. JAMA 1999;281:1291-7.

25 Gregg EW, Gu Q, Cheng YJ, Narayan KM, Cowie CC. Mortality trends in men and women with diabetes, 1971 to 2000. Ann Intern Med 2007;147:149-55.

26 Holmen J, Midthjell K, Bjartveit K, Hjort PF, Lund-Larsen PG, Moum T, et al. The North-Trøndelag health survey 1984-86. Purpose, background and methods. Participation, non-participation and frequency distribution. Report No 4. Oslo, Norway: Statens Institutt for Folkehelse, Senter for Samfunnsmedisinsk Forskning, 1990.

27 Holmen J, Midthjell K, Krüger $\varnothing$, Langhammer A, Holmen TL, Bratberg GH, et al. The Nord-Trøndelag health study 1995-97 (HUN 2): objectives, contents, methods and participation. Nor J Epidemiol 2003:13:19-32

28 Koopman RJ, Mainous AG, Diaz VA, Geesey ME. Changes in age at diagnosis of type 2 diabetes mellitus in the United States, 1988 to 2000. Ann Fam Med 2005:3:60-3.

29 UK Prospective Diabetes Study Group. Tight blood pressure control and risk of macrovascular and microvascular complications in type 2 diabetes: UKPDS 38. BM/1998:317:703-13.

30 Saydah SH, Fradkin J, Cowie CC. Poor control of risk factors forvascular disease among adults with previously diagnosed diabetes. JAMA 2004:291:335-42.

31 Norhammar A, Malmberg K, Ryden L, Tornvall P, Wallentin L. Under utilisation of evidence-based treatment partially explains the unfavourable prognosis in diabetic patients with acute myocardial infarction. Eur Heart / 2003;24:838-44.

32 Arnett DK, McGovern PG, Jacobs DR, Shahar E, Duval S, Blackburn H, et al. Fifteen-year trends in cardiovascular risk factors (1980-1982 through 1995-1997): the Minnesota heart survey. Am J Epidemiol 2002;156:929-35.

33 Midthjell K, Krüger Ø, Holmen J, Tverdal A, Claudi T, Bjorndal A, et al. Rapid changes in the prevalence of obesity and known diabetes in a adult Norwegian population. The Nord-Trøndelag health surveys: 1984-1986 and 1995-1997. Diabetes Care 1999:22:1813-20.

34 Bogers RP, Bemelmans WJ, Hoogenveen RT, Boshuizen HC, Woodward M, KnektP, et al. Association of overweight with increased risk of coronary heart disease partly independent of blood pressure and cholesterol levels: a meta-analysis of 21 cohort studies including more than 300000 persons. Arch Intern Med 2007;167:1720-8.

35 Unal B, Critchley JA, Capewell S. Explaining the decline in heart disease mortality in England and Wales between 1981 and 2000. Circulation 2004:109:1101-7.

36 McGuire DK, Rao SV, Joski P, Barsness GW, Peterson ED, Jollis JG, et al. Diabetes is associated with a higher risk of death than is prior myocardial infarction in the setting of coronary disease: results from the Duke Cardiovascular Database. I Am Coll Cardio 2002;39:329A. (Abstract.)

37 Tran CT, Laupacis A, Mamdani MM, Tu JV. Effect of age on the use of evidence-based therapies for acute myocardial infarction. Am Heart 2004;148:834-41.

38 Arciero TJ, Jacobsen SI, Reeder GS, Frye RL, Weston SA, Killian IM, et a Temporal trends in the incidence of coronary disease. Am / Med 2004; 117:228-33.

39 Huxley R, Barzi F, Woodward M. Excess risk of fatal coronary heart disease associated with diabetes in men and women: meta-analysis of 37 prospective cohort studies. BMJ 2006;332:73-8.

40 Hunink MG, Goldman L, Tosteson AN, Mittleman MA, Goldman PA, Williams LW, et al. The recent decline in mortality from coronary heart disease, 1980-1990. The effect of secular trends in risk factors and treatment. JAMA 1997;277:535-42.

41 Midthjell K, Holmen J, Bjørndal A, Lund-Larsen G. Is questionnaire information valid in the study of a chronic disease such as diabetes? The Nord-Trøndelag diabetes study. J Epidemiol Community Health 1992:46:537-42.

42 Cho E, Rimm EB, Stampfer MJ, Willett WC, Hu FB. The impact of diabetes mellitus and prior myocardial infarction on mortality from al causes and from coronary heart disease in men. I Am Coll Cardiol 2002;40:954-60.

43 Kehoe R, Wu SY, Leske MC, Chylack LT. Comparing self-reported an physician-reported medical history. Am J Epidemiol 1994;139:813-8.

Accepted: 24 April 2008 